\title{
SUGRA: TOKOH PERINTIS DAN DINAMIKA TARLING INDRAMAYU (1930-1997)
}

\section{SUGRA: THE PIONEER AND THE DYNAMICS OF TARLING MUSIC DEVELOPMENT IN INDRAMAYU (1930-1997)}

\author{
Lasmiyati \\ Balai Pelestarian Nilai Budaya Jawa Barat \\ Jln. Cinambo 136 Ujungberung Bandung \\ e-mail: lasmiyatinizam@gmail.com
}

\begin{abstract}
Abstrak
Penelitian tentang Sugra dilakukan dengan tujuan untuk mengenang tokoh perintis tarling di Indramayu yang selama ini kurang dikenal di kalangan luas. Penelitian ini menggunakan metode sejarah dengan pendekatan sejarah biografi. Pengumpulan data dilakukan dengan wawancara, studi lapangan, dan studi pustaka. Hasil yang diperoleh dari penelitian ini menunjukkan bahwa tokoh tarling di Indramayu dibedakan menjadi dua: tokoh perintis dan tokoh pengembang. Tokoh perintis adalah Sugra. Ia hanya menekuni kesenian tarling di wilayah Indramayu, walaupun pernah bermain tarling di Cirebon. Tokoh pengembang adalah mereka yang mampu mengembangkan kesenian tarling ke Cirebon, walaupun mereka berasal dari Indramayu. Walaupun Sugra hanya bermain tarling di Indramayu, masyarakat Indramayu tetap menganggap Sugra sebagai perintis tarling. Sugra juga mampu mengajak pemuda Kepandean untuk bermain tarling, walaupun peralatannya masih sederhana. Tugu tarling didirikan di tempat Sugra merintis kesenian tarling. Nama Sugra pun diabadikan menjadi nama gedung kesenian Mama Soegra dan rumah seni Griya Sugra.
\end{abstract}

Kata kunci: Sugra, tarling, Indramayu.

\begin{abstract}
The study on Sugra was carried out with the aim of perpetuating the existence of the Indramayu tarling music pioneer for the reason of his less well-known. It used the historical methods with a biographical historical approach. The data was collected by means of interviews, field studies, and literature studies. Studies have shown that the leading figures of tarling music in Indramayu involved the pioneer and the settlers. The pioneer was Sugra. He devoted himself to his work as a tarling musician in Indramayu. Furthermore, he also promoted tarling music in Cirebon. Moreover, settlers were generally those originating from Indramayu and were considered as the key musicians in the development of tarling music in Cirebon. Despite Sugra's stage was limited in Indramayu, the locals still consider him as the pioneer of tarling. With his simple musical instruments, he visited a group of youths in Kepandean sub-district, playing music, and conducting sing-alongs. A monument forming tarling musical performance was erected in Indramayu to his memory. His name was even continued in that of two art galleries Mama Soegra and Griya Sugra.
\end{abstract}

Keywords: Sugra, tarling, Indramayu.

\section{A. PENDAHULUAN}

Tokoh adalah orang yang terkemuka dan kenamaan dalam bidang politik, kebudayaan, dan sebagainya (Tim Penyusun KBBI, 2011: 1476). Berbicara tentang tokoh akan membicarakan hidup seseorang dari lahir hingga meninggal. Tokoh yang menguasai bidang tertentu hingga ia mendapatkan pengakuan dari masyarakat maka bidang ketokohannya 
disesuaikan dengan bidang yang ia tekuni. Apabila tokoh tersebut menekuni seni maka ia mendapatkan julukan sebagai tokoh seni.

Kabupaten Indramayu berbatasan dengan Laut Jawa di sebelah utara, di sebelah selatan berbatasan dengan Kabupaten Majalengka, Sumedang, dan Cirebon, di sebelah barat berbatasan dengan Kabupaten Subang, dan di sebelah timur berbatasan dengan Laut Jawa dan Kabupaten Cirebon (Tim Litbang Kompas, 2003: 230). Di Kabupaten Indramayu terdapat jenis kesenian seperti berokan, brai, dombret, genjring, umbul, jidur, macapat, renteng, ronggeng ketuk, rudat, sampyong, sandiwara, sintren, tarling, tayuban, topeng, terbang, wayang golek cepak, dan wayang purwa. Tarling merupakan kesenian khas di Indramayu dan Cirebon. Supali Kasim mengatakan bahwa tarling merupakan kesenian asli Indramayu, adapun kesenian lainnya, bukan kesenian asli Indramayu disebabkan kesenian selain tarling merupakan kesenian yang mendapat pengaruh dari Jawa Tengah dan Jawa Timur. Tarling dapat dikatakan sebagai kesenian asli Indramayu juga diungkapkan oleh Sunarto Martaatmadja atau yang akrab disapa Kang Ato. Dalam Sarasehan Budaya Apresiasi Seni Tarling Klasik "Mengenang Sugra" di Gedung Panti Budaya Indramayu pada 15 September 2014. Kang Ato yang waktu itu sebagai pembicara bersama Supali Kasim dan Nurochman Sudibyo Y. S., mengatakan bahwa kesenian tarling berasal dari Indramayu dan diciptakan di Indramayu oleh Ki Sugra (alm.) dari Kepandean Indramayu tahun 1930 (Martaatmadja, 2014). Tarling dapat disebut sebagai kesenian asli Indramayu karena Mang Talan, warga Kepandean Indramayu, pernah kedatangan warga Belanda yang menservis gitarnya yang rusak. Akan tetapi setelah sekian lama, gitar yang selesai diservis tersebut tidak diambilnya. Sugra putera Mang Talan, mempelajari nada yang ada dalam gitar tersebut, dan mampu mensinkronkan antara nada yang ada di gamelan dengan petikan-petikan gitar. Nada yang ada dalam gitar dipelajari dan dibandingkan dengan nada-nada yang ada dalam gamelan. Ternyata Mang Talan dapat mensinkronkan antara suara gamelan dengan petikan-petikan gitar (Kasim, wawancara 15 Juli 2016).

Mang Talan memiliki putra bernama Sugra. Ia mewarisi profesi ayahnya sebagai pemain gamelan. Sugra pun belajar memetik gitar yang disesuaikan dengan nada yang ada dalam gamelan. Pertanyaan yang dapat diajukan kemudian, bagaimanakah perjalanan Sugra dari pewaris pemain gamelan hingga ia menggeluti kesenian tarling.

Dalam artikel ini penulis membahas mengenai sosok Sugra sekaligus menjawab pertanyaan tentang bagaimana perjalanan Sugra berkecimpung dalam ranah seni tarling. Ruang lingkup penelitian ini mengambil lokasi di Kabupaten Indramayu dan dibatasi dalam kurun waktu 1930 1997.

Tulisan mengenai tarling telah dilakukan oleh beberapa orang baik di jurnal penelitian ataupun skripsi, akan tetapi penelitian tentang profil Sugra masih jarang dilakukan. Artikel terdahulu yang berkaitan dengan tarling, di antaranya adalah artikel Nina Merlina (2012) dengan judul "Tarling Kesenian Tradisional Daerah Pantura: Suatu Kajian Nilai Budaya." Dalam artikelnya Nina mengklasifikasi antara tokoh tarling dan perintis tarling yang terbagi kedalam beberapa generasi. Generasi pertama adalah Sugra. Sugra merupakan sosok yang mengantarkan tarling sebagai sebuah kesenian yang berhasil mengusung lagulagu daerah dengan menggunakan alat musik dari daratan Eropa. Kedua adalah generasi Jayana dan Raden Sulam. Ia yang membawa tarling menjadi sebuah tontonan yang lebih memikat. Jayana adalah orang pertama yang membawa tarling menjadi sebuah kesenian pertunjukan yang memukau dan meresap di hati masyarakat pantai utara Indramayu dan Cirebon. 
Ketiga, generasi Uci Sanusi. Ia memiliki grup orkes keroncong pada tahun 1950-an. Uci melengkapi alat musik tarling dengan goong, kendang, tutukan, dan kecrek. Dari artikel Nina Merlina (2012) tersebut, nama Sugra tidak disinggung secara mendalam. Adapun artikel Salim (2015) berjudul "Perkembangan dan Eksistensi Musik Tarling Cirebon.” Salim berpendapat bahwa perkembangan musik tarling dapat dikelompokkan menjadi tiga periodisasi, yaitu periodisasi musik, periodisasi lagu dan lawak, serta periodisasi teater. Tahun 1930, musik tarling ditemukan oleh Pa Barang, warga keturunan Cina. Oleh karena kegigihannya, ia menemukan nada-nada gamelan dalam gitar. Menurut Jana, yang diwawancari oleh Salim, mengatakan bahwa Pa Barang memiliki keahlian dalam memetik gitar, nyuling, nembang. Nada yang dimainkan dengan gitar, mengikuti motif pukulan memainkan gamelan kemudian disebut tarling. Dari kedua artikel tersebut tidak satu pun yang menyinggung tentang peran Sugra dalam seni tarling.

Riyan Hidayat (2015) juga menulis artikel "Seni Tarling dan Perkembangannya di Cirebon." Hidayat membagi musik tarling menjadi dua yaitu musik lagu-lagu tarling klasik dan musik/lagu-lagu tarling irama Cirebon modern. Komposisi tarling klasik dimodifikasikan dari karya seni karawitan Sunda, dimainkan dalam laras pelog seperti kiser saidah, cerbonan, dermayonan, lagu tarling klasik. Adapun tarling irama adalah tarling dan irama yang menggunakan lagu tarling modern yang terdiri atas irama Cirebonan beraturan dan irama Cirebonan tidak beraturan. Riyan Hidayat (2015) juga menyinggung tokoh tarling di Indramayu. Riyan mengklasifikasi ke dalam pemusik yaitu Didik Junaedi, Jayana, dan H. Wakyad; pencipta lagu yaitu Jayana, H. Dariyah, Yoyo Sunaryo, M. Sadi, dan lain lain; penyanyi yaitu Dadang Diniah, $\mathrm{H}$. Dariyah, Carminah, Yoyo Sunaryo, dan lain-lain.
Artikel selanjutnya ditulis oleh Yeni Mulyani Suprihatin (2012) dengan judul mengenai "Teks Tarling: Representasi Sastra Liminalitas (Analisis Fungsi dan Nilai." Dalam artikelnya, Yeni berpendapat bahwa fungsi utama sastra Jawa Cirebon dalam seni tarling adalah untuk hiburan. Fungsi hiburan tersebut tampak dari sikap pelaku dan penonton tarling yang mempunyai prinsip sing penting biso joget, bli peduli critane opo (yang penting joget tidak peduli ceritanya apa). Selain sebagai hiburan, tarling sebagai sarana mengekspresikan diri yang penuh kepedihan. Lirik lagu-lagu tarling yang dinyanyikan disebut dengan tarling klasik yang diciptakan dalam bentuk wangsalan, panting/ungkapan lain. Adapun nilai yang terkandung dalam tarling, mengandung nilai egaliter dan kesederajatan yang tidak membedakan kasta. Kedua, tarling mengandung filosofi yaitu yen wis mlatar kudu bisa eling. Setelah hidup urakan harus bisa bertobat. Tarling pun dipandang sebagai peelingeling.

Dalam artikel ini penulis menggunakan teori peran individu sebagai subjek sejarah. Dalam teori ini peran individu atau kelompok seseorang sangat menentukan dalam konteks sebagai subjek atau pelaku suatu peristiwa sejarah. Dalam teori tersebut dijelaskan bahwa peran seseorang merupakan hasil interaksi dari diri (self), dengan posisi status dalam masyarakat dan dengan peran akan menyangkut perbuatan yang punya nilai dan normatif. Individu atau aktor sebagai pelaku peristiwa dan hasil perbuatan sebagai objek peristiwa sejarah mempunyai hubungan erat yang bersifat kontinu dan temporal (Tamburaka, 1999: 80).

Artikel ini dibuat dengan pendekatan sejarah biografi, yaitu catatan hidup seseorang. Kuntowijoyo (2003: 206) mengatakan bahwa dalam setiap biografi mengandung empat permasalahan yaitu kepribadian tokohnya, kekuatan sosial yang mendukung, lukisan sejarah 
zamannya, keberuntungan, keterpihakan yang datang. Sehubungan dengan kepribadian tokoh, sebuah biografi perlu memperhatikan adanya latar belakang keluarga, pendidikan, lingkungan sosial budaya, dan perkembangan diri (Kuntowijoyo, 2003: 207).

Selain itu, tulisan ini juga dilakukan dengan pendekatan kesinambungan (continuity), keragaman (divercity), dan perubahan (change) (Muhsin, 2002: 35). Kingley Davis, sebagaimana yang dikutip oleh Sukanto (1982: 306) mengartikan bahwa perubahan-perubahan sosial sebagai perubahan-perubahan yang terjadi dalam struktur dan fungsi masyarakat. Misalnya timbulnya pengorganisasian buruh dalam masyarakat kapitalis, menyebabkan perubahan-perubahan dalam hubungan antarburuh dengan majikan yang kemudian menyebabkan perubahan-perubahan dalam organisasi dan politik. Adapun Mac Iver sebagaimana yang dikutip oleh Sukanto (1982: 306) membedakan antara utilitarian element dengan cultural elements yang didasarkan pada kepentingan-kepentingan manusia yang primer dan sekunder. Semua kegiatan dan ciptaan manusia dapat diklasifikasikan ke dalam dua kategori tersebut. Culture menurut Mac Iver adalah ekspresi dari jiwa yang terwujud dalam cara-cara hidup dan berpikir, pergaulan hidup, seni, kesusasteraan, agama, rekreasi, hiburan, sebuah novel drama, film, permainan, filsafat, dan sebagainya, termasuk ke dalam culture. Oleh karena hal-hal tersebut secara langsung memenuhi kebutuhan manusia. Menurut Mac Iver bahwa perubahan-perubahan dalam hubungan sosial atau sebagai perubahan terhadap keseimbangan hubungan sosial tersebut (Sukanto \& Sulistyowati, 1985: 306-307).

Adapun Fraenkel, sebagaimana dikutip oleh Susanto (1983: 159) mengatakan bahwa kemajuan teknologi tidak saja merupakan modifikasi dari suatu bagian ilmu pengetahuan, akan tetapi mempunyai akibat mengubah pola pikir manusia dan mengubah pola/struktur sosial secara keseluruhan. Masih menurut Fraenkel bahwa manusia berusaha mengikuti perubahan teknologi dengan akibat peradaban masyarakatnya tanpa mengarahkannya ke arah kemunduran (regress), tetapi menjadikannya suatu kemajuan (progress) untuk manusia.

\section{B. METODE PENELITIAN}

Metode yang digunakan pada artikel ini adalah metode sejarah yang meliputi empat tahapan kerja. Pertama, tahap heuristik, yaitu tahap mencari dan menemukan sumber, baik sumber primer maupun sekunder. Langkah yang dilakukan antara lain berupa persiapan lapangan yang meliputi pengurusan surat izin penelitian dan studi pustaka, dilanjutkan dengan pencarian data lapangan. Selain itu dalam penelitian ini juga dilakukan wawancara. Wawancara dilakukan dengan budayawan dan penulis Indramayu, pemuda dari Desa Kepandean yang sangat peduli dengan kesenian tarling, keluarga Sugra, serta dengan staf Dinas Kebudayaan dan Pariwisata Kabupaten Indramayu. Dari hasil wawancara yang diperoleh selanjutnya dicocokkan dengan sumbersumber tertulis yang didapat.

Kedua, tahap kritik sumber yang bertujuan untuk mengetahui apakah dari sumber-sumber tersebut valid dan dapat dipercaya. Setelah sumber-sumber dikritik baik ekstern maupun intern, langkah berikutnya mengolah sumber untuk mendapatkan data yang diperlukan. Setelah data terkumpul kemudian diklasifikasi disesuaikan dengan subbab yang akan ditulis. Tahap ketiga adalah tahap interpretasi, baru kemudian dilakukan penulisan atau historiografi sebagai tahap terakhir, yaitu merangkaikan fakta hingga menjadi tulisan sejarah.

\section{HASIL DAN BAHASAN \\ 1. Selayang Pandang Kabupaten Indramayu}

Menurut Dasuki (1977: 27) sebagaimana ia merujuk catatan Tome Pires, menyatakan bahwa pada awal abad ke-16, di Indramayu 
sudah ada pelabuhan yang cukup besar dan banyak pedagang asing dari berbagai negeri bermukim di Pelabuhan Cimanuk. Mereka melakukan perdagangan dengan penduduk setempat. Menurut Dasuki (1977: 122) yang mengutip pendapat Jayadiningrat, menyatakan bahwa Pelabuhan Cimanuk ramai didatangi pedagang muslim seperti dari Arab, Parsi, India, dan Cina. Dalam catatan Tome Pires, Cimanuk merupakan pelabuhan kedua setelah Sunda Kelapa. Supali Kasim mengatakan bahwa badan Sungai Cimanuk cukup lebar, sehingga dapat dilalui kapal dari lepas pantai, hingga menuju pusat kota di Desa Dermayu. Lokasi pelabuhan diperkirakan ada di Desa Pasekan. Jejak dari Pelabuhan Cimanuk masih melekat dengan adanya nama-nama desa yang letaknya tidak jauh dari muara Cimanuk seperti Desa Pagirikan, Paseban, Pabean, dan Paoman. Dilihat dari arti kata, keempat desa ini menggambarkan aktivitas masyarakat di pelabuhan seperti pabean yang artinya pengambilan bea masuk bagi kapal-kapal di pelabuhan. Pagirikan yang berasal dari kata girik, yang artinya pengurusan surat-surat untuk kapal. Pasekan yang artinya tempat bongkar muat barang, Paoman yang berasal dari kata paomah-an yang artinya perumahan para pegawai pelabuhan (Kasim, 2016: 58).

Bandar Pelabuhan Cimanuk tidak digunakan untuk jung-jung atau kapal layar besar, kapal layar besar dapat berlabuh hanya di lepas pantai pelabuhannya. Bandar pelabuhan ini memiliki tempat perdagangan dan kota pemukiman yang luas dan ramai.

Pedagang yang singgah di pelabuhan ini adalah pedagang dari Tiongkok (Cina), Arab, India, dan Eropa (Portugis dan Belanda). Para pedagang biasanya menetap dalam jangka waktu yang tidak menentu. Untuk kembali ke tanah airnya mereka singgah di bandar pelabuhan dalam jangka waktu yang tidak menentu, hal itu karena faktor cuaca dan angin yang harus sesuai dengan arah pelayaran mereka. Untuk mengisi waktu luangnya tidak sedikit dari para pedagang tersebut memainkan jenis alat musik mereka. Pedagang Portugis misalnya memainkan keroncong dengan alat musik gitar, baik gitar frorengan, gitar monica, dan gitar jitera. Kesenian keroncong inilah yang nantinya juga menjadi kesenian bangsa Indonesia.

Selain bangsa Portugis, bangsa Belanda juga memiliki kesenian Tonel ${ }^{1}$ yang dimainkan untuk menghibur para serdadu Belanda. Dengan adanya para pedagang yang berlabuh di Pelabuhan Cimanuk tersebut secara tidak langsung meninggalkan jejak kesenian. Adapun kesenian yang ada saat ini merupakan kesenian yang akhir dari proses sejarah kebudayaan hibrid (percampuran) (Nugroho, 2016: 103). Seni-seni yang menjadi pembuktian sejarah akulturasi di Pelabuhan Cimanuk adalah berokan, dombret, genjring, umbul, jidur, macapat, renteng, ronggeng ketul, rudat, sampyong, sandiwara, sintren, tayuban, tari topeng, trebang, wayang golek cepak, dan tarling.

Tarling merupakan jenis kesenian yang diambil dari kata gitar dan suling. Dua jenis alat musik ini dipadukan sehingga menjadi sebutan tarling. Tarling tumbuh di Indramayu dan berkembang di pantura (Indramayu dan Cirebon). Supali Kasim (2007: 11) mengatakan bahwa tokoh tarling di Indramayu terbagi ke dalam tokoh perintis dan tokoh pengembang. Tokoh perintis adalah Sugra. Adapun tokoh pengembang adalah Jayana. Pria kelahiran Karangampel Indramayu ini piawai dalam memainkan gitar. Jayana

\footnotetext{
${ }^{1}$ Dalam tulisan Ki Hajar Dewantara sebagaimana yang dikutip Dede Pramayoza (2015: 124), mengartikan bahwa Sandiwara atau Drama atau Tonil ialah kesenian kesusasteraan yang diwujudkan sebagai percakapan dengan disertai pemain-pemain dramatis/personal untuk melakukan segala percakapan dengan diiringi gerak dan laku agar dapat mewujudkan ceritanya sebagai keadaan yang nyata-nyata kejadian. Dede juga menampilkan gambar (foto) bahwa alat musik yang dibawakannya adalah gitar. Dede Pramayoza (2015: 124),
} 
pernah belajar tarling kepada Sugra. Jayana yang dapat mengangkat dan mengenalkan tarling kepada masyarakat. Jayana dapat mengembangkan kesenian tarling ke wilayah Cirebon. Pada kota tersebut tarling menjadi sebuah industri hiburan, apalagi unsur-unsur peralatan modern sudah mulai tersedia seperti panggung, listrik, dan pengeras suara. Tokoh pengembang lainnya adalah Sunarto. Sunarto yang pernah belajar tarling kepada Sugra juga mengembangkan tarlingnya ke wilayah Cirebon.

\section{Sugra}

Sugra lahir di Desa Kepandean Kecamatan Indramayu Kabupaten Indramayu. Ayahnya bernama Talan yang menggeluti bidang gamelan dan seni kidung. Sugra adalah putra ketiga dari tiga bersaudara. Kedua kakaknya bernama Yaman dan Maskani. Sugra menikah dengan Daniah dan memiliki satu anak perempuan bernama Suniah (Nono/cucu Sugra, wawancara 17 Desember 2019). Pendidikan yang ditempuh Sugra hanya sampai Sekolah Dasar.

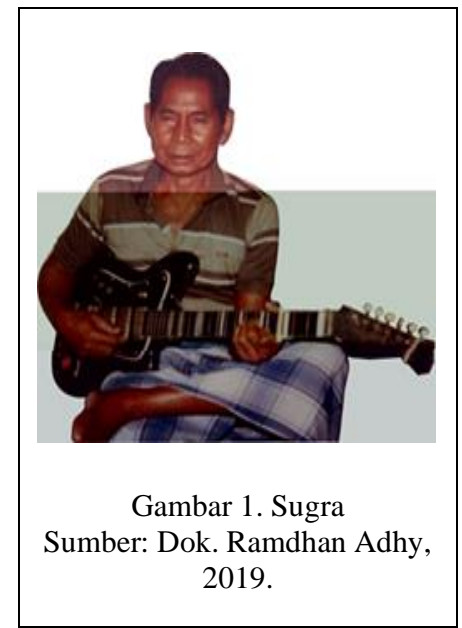

\section{Dinamika Tarling Indramayu}

\section{a. Kekuatan Sosial yang Mendukung}

Sugra sebagai tokoh perintis tarling, bukan hanya perintis tarling di Indramayu, melainkan juga di wilayah pantai utara, dalam arti wilayah kebudayaan Cirebon ${ }^{2}$. Kiprah Sugra di kesenian tarling diawali ketika gitar milik komisaris Belanda yang diperbaiki oleh Talan tidak diambil oleh pemiliknya. Oleh Talan (ayah Sugra) yang ahli gamelan dan pembaca kidung, gitar tersebut dipelajari nada-nadanya.

Keahlian Talan dalam gamelan diturunkan kepada putranya Sugra. Sugra pun ikut mendalami nada-nada yang ada dalam gitar. Ia juga menguasai nada-nada yang ada dalam gamelan. Gamelan terdiri atas lima nada yaitu tugu, loloran. panelu, galimer, dan singgul, selanjutnya disebut dengan nama notasi huruf $(\mathrm{t}, \mathrm{l}, \mathrm{p}, \mathrm{g}, \mathrm{s})$. Selain notasi huruf juga ada notasi angka yang disebut da-mi-na-ti-la (1 da, $2 \mathrm{mi}, 3$ na, 4 ti, 5 la) (Upandi \& Hadi, YS., 2011: 5). Dari nada yang ada dalam gamelan, tampaknya Talan tidak paham notasi doremi. Talan hanya paham dengan notasi

\footnotetext{
${ }^{2}$ Cirebon yang awalnya bernama Caruban Nagari wilayahnya dari Kali Cilosari di timur sampai batas Kabupaten Indramayu di utara dan sebagian besar daerah Kabupaten Cirebon sekarang. Hingga abad ke-15, wilayah eks Kabupaten Cirebon masuk wilayah Galuh yang meliputi Kabupaten Majalengka, Cirebon, Kuningan, dan Indramayu sekarang. Pangeran Cakrabuana yang membawahi Caruban Nagari harus tunduk kepada raja di Galuh dan menyerahkan upeti (Sunardjo. 1983: 9-10). Lama-kelamaan Kerajaan Galuh mulai melemah yang berpengaruh kepada kemampuan dalam pengendalian kekuasaan politik di wilayah kekuasaannya, khususnya di wilayah pesisir utara, Dengan melemahnya kekuasaan Galuh, nagari bawahannya diberikan otonomi penuh, nagari-nagari itulah kemudian masuk Kabupaten Cirebon. Nagari yang diberikan otonomi penuh dan masuk ke wilayah Kabupaten Cirebon tersebut masih berlanjut ketika terjadi penandatanganan perjanjian antara pemerintah Belanda dengan ketiga sultan Cirebon (sultan Kasepuhan, Kanoman, dan Kacirebonan). Hasil dari penandatanganan perjanjian tersebut wilayah Cirebon meliputi Kandanghaur, Indramayu, Kuningan, Majalengka, dan Kabupaten Cirebon (Dasuki, 1977: 167) Setelah Indonesia merdeka wilayah eks Kabupaten Cirebon yang dahulunya masuk wilayah Cirebon seperti Kabupaten Majalengka, Kuningan, dan Indramayu menjadi kabupaten sendiri, walaupun demikian secara wilayah kultural, Cirebon merupakan pusat kebudayaan pada wilayah kultural Cirebon (Supali Kasim, wawancara, 17 Desember 2019).
} 
diatonis, sementara notasi pentatonis tidak dikuasainya. Di sisi lain Sugra yang sudah menguasai nada-nada dalam gitar dan dapat memadukannya dengan nada-nada gamelan. Grade-gradenya dibuat pentatonis sehingga lahirnya alunan gitar pentatonis Dermayu. Alunan gitar dan gamelan itu adalah bunyi-bunyian tembang klasik, yaitu temponya lambat, tidak ada syair lagu, yang ada kerangka lagu (wirahma). Dari petikan gitar bernada gamelan tersebut terciptalah tembangtembang kiser, yaitu ciri lagu tarling klasik yang lambat.

Tembang tarling awalnya tergolong ke dalam lagu yang tidak memiliki ketukan. Iramanya bebas tetapi ada aturan panjang pendek tertentu yang tidak bisa dituliskan. Dalam sistem laras lagu Sunda, irama tersebut digolongkan sebagai sekar wirahma mardika. Penentuan panjang pendek tertentu yang tidak bisa diajarkan secara verbal dari seorang guru kepada murid. Masyarakat Indramayu menyebutnya jenis lagu ini sebagai jenis lagu klasikan. Tembang yang cukup popular seperti jonggrang, kiser, dermayonan, cerbonan dengan menggunakan laras pentatonik. Lagu dan liriknya serupa dengan lagu-lagu yang berkarakter elegi (kesedihan) maupun balada (lagu-lagunya panjang). Lirik lagulagu tarling tidak baku, akan tetapi berisikan syair-syair yang secara cerdas diungkapkan seketika menurut tema lagunya. Syair tarling berisikan sastra wangsalan, parikan, paribahasa dan purwakanti. Tembang tarling kreasi merupakan suatu kreasi dari tembang macapat atau tembang cilik yang sudah dikenal sebelumnya sebagai jenis tembang di Jawa. Fase tarling klasik ini lagulagunya tidak ada teks baku, wirasuara (pesinden) menyanyikan syairnya tanpa teks, tetapi mengikuti ketukan guru wilangan, mengikuti karakter sedih, dan nelangsa. Dari lagu-lagu tersebut muncullah cerita yang ditembangkan misalnya Kiser Saedah - Saenih yang ditembangkan sampai selesai.

\section{b. Perubahan Sosial Masyarakat}

Dalam suatu masyarakat kadang mengalami perubahan sosial baik yang bersifat statis dan dinamis. Statis yaitu masyarakat yang lambat dan sedikit sekali mengalami perubahan dan masyarakat dinamis yaitu masyarakat yang cepat mengalami perubahan (Soekanto \& Sulistyowati, 2015: 258). Perubahan masyarakat juga dialami oleh warga Kepandean. Memasuki tahun 1930, Sugra sudah menjadikan gitar sebagai alat musik yang merakyat. Bagi Sugra, gitar bukan lagi alat musik milik bangsa Eropa. Ia mampu membawakan Lagu-lagu dermayonan yang diiringi dengan suara petikan gitar. Petikan gitar yang membawakan lagu-lagu dermayonan tersebut mulai disukai kalangan anak-anak muda Kepandean. Kalangan pemuda Kepandean mulai menyukai gitar dan suling. Mereka mulai mencoba membuat gitar dengan bahan yang sangat sederhana, termasuk ada yang membuat gitar dari bahan seng, sehingga ketika kawatnya dipetik bunyinya sember. Tarling yang digelar tahun 1930-an, waktu itu belum ada panggung, listrik, dan belum ada pengeras suara. Meskipun demikian, pengaruh Sugra sangat luas karena dibuktikan tarling pada masanya digemari banyak anak muda yang sengaja belajar tarling, dan mereka berupaya membeli alat gitar, instrumen gitar yang waktu itu merupakan alat musik bangsa Eropa.

Tahun 1936-an, suara tembang dermayonan atau cerbonan yang diiringi gitar mulai mewabah di kalangan anak muda. Anak-anak muda di Indramayu sudah mulai berkeinginan memiliki gitar sendiri. Selain membeli, ada pula yang membuat gitar sendiri dengan bahan yang sederhana. Gitar waktu itu masih merupakan barang langka. Menurut Sugra, para pemuda berhasil patungan dari hasil menanam padi atau menjual gabah untuk membeli gitar. Dari patungan tersebut mereka membeli alat perkusi lain seperti kotak sabun yang berfungsi sebagai kendang, logam seng sebagai kecrek, 
ditambah dengan ketipung kecil, dan baskom sebagai goong. Alat musik yang dibawakan Sugra sudah ditambah dengan ketipung kecil sebagai alat perkusi dan membeli peralatan lainnya. Sugra juga menambahkan suling. Lagu-lagu yang dibawakannya pun meliputi dermayonan, cerbonan, keranginan, dan renggong. dahulunya bernama Kiser Gede (Supali Kasim, wawancara 17 Desember 2019).

Hampir semua manusia pada awalnya merupakan anggota kelompok sosial yang dinamakan keluarga. Kalau anggota kelompok tersebut menyebar, tapi suatu saat mereka akan berkumpul kembali entah itu berkumpul bersama keluarga atau hanya makan bersama. Dalam hubungannya dengan kelompok sosial di luar rumah, anggota keluarga memiliki pengalaman yang berbeda-beda, entah itu hanya sekadar berkumpul, atau tukar menukar pengalaman. Tanpa disadari dari berkumpul dan tukar menukar pengalaman tersebut akan mengubah kepribadian orang yang bersangkutan (Sukanto \& Sulistyowati, 2015: 100). Begitu halnya dengan Sugra, ia terkadang mengambil kesempatan untuk berkumpul dengan pemuda Kepandean, di dekat warung ujung gang. Mereka berkumpul sambil memainkan tarling. Dengan lagu-lagu dermayonan, Sugra dapat menarik perhatian pemuda sekitarnya untuk bersama-sama bermain tarling. Selain itu, rumah Sugra juga dijadikan sebagai tempat tongkrongan para pemuda, Sambil ngobrol mereka pun bermain tarling. Di malam hari, Sugra sering terlihat berkumpul bersama-sama dengan warga masyarakat khususnya para pemuda. Mereka menyanyikan lagu-lagu dermayonan dengan iringan musik yang masih sederhana. Berdekatan dengan rumah Sugra, ada sebuah gang kampung. Di pojok gang ada sebuah warung, di situlah Sugra berkumpul bersama para pemuda Kepandean. (Ramdhan, wawancara 17 Desember 2019).

Mewabahnya bermain tarling yang dibawakan Sugra dan pemuda-pemuda di
Kepandean, akhirnya meluas hingga ke Karangampel. Pemuda Jayana yang berasal dari Karangampel (kurang lebih $25 \mathrm{~km}$ dari Indramayu) ikut bergabung bersama Sugra, bahkan Jayana mencoba-coba membuat gitar sendiri. Tahun itulah rombongan tarling Sugra sudah memiliki 3 buah gitar, satu seruling, kecrek, dan ketipung kecil (Kasim, 2007: 7).

Dari situlah masyarakat Kepandean mulai ada yang menanggap Sugra untuk bermain tarling. Oleh karena peralatannya juga masih sederhana, pada saat Sugra bermain tarling, ia belum mendapat bayaran. Ia hanya diberi suguhan seperti yang pernah Sugra katakan: "bayaran duit durung ana, sing ana iku panganan, balikna digawani brongkosan" (artinya: honor belum ada, yang ada mendapatkan suguhan makanan, pulangnya diberikan suguhan makanan).

Panggung kesenian pada masa Sugra juga jauh dibandingkan dengan panggung kesenian tarling pada saat ini. Pertunjukan atas permintaan orang digelar di halaman rumah. Itu semata-mata untuk menghibur tanpa mengharapkan imbalan. Properti juga masih sederhana, yaitu tanpa penerangan. Penerangan yang Sugra gunakan masih menggunakan lampu tempel, terkadang masih menggunakan petromak dan pengeras suara yang sederhana. Peralatan kesenian yang ia gunakan pun masih sangat terbatas.

Pada tahun 1935, rombongan tarling pimpinan Sugra pertama kali dipanggil orang untuk mementaskan kesenian tarling untuk mengisi acara puputan atau melekan di rumah warga. Pada tahun itu ia belum mendapatkan honor uang. Ia hanya mendapatkan suguhan makanan dan pulangnya diberi bungkusan makanan. Kondisi masyarakat waktu itu yang segalanya masih sederhana. Mereka mengundang kelompok kesenian untuk acara-acara keluarga, seperti khitanan (sunatan untuk anak laki-laki), rasulan (keluarga yang tidak memiliki anak lakilaki, dan syukuran untuk kelahiran anak perempuan), atau ruwatan, seperti sebuah 
keluarga yang hanya memiliki anak tunggal, baik laki-laki ataupun perempuan. Pada momen-momen seperti itulah Sugra mendapat panggilan untuk bermain tarling. Panggilan kepada Sugra untuk bermain tarling juga pada acara tanggapan keluarga yang mengundang tetangga ketika ngobong bata (membakar batu-bata). Pada musim kemarau ada tradisi masyarakat Indramayu yang biasa membuat batu bata sendiri. Ketika ada masyarakat yang membuat batu bata biasanya dibutuhkan waktu pembakaran yang cukup lama. Ketika membakar batu bata tersebut diadakan syukuran.

Dalam acara membakar batu bata, waktu yang diperlukan adalah semalam suntuk, untuk itu harus ditunggu agar sistem pembakarannya merata dan apinya tidak mati. Agar tidak merasa sepi, mereka membuat acara mengundang masyarakat sekitar melalui acara makan-makan dan mengundang Sugra untuk bermain tarling. Dari momen seperti inilah nama Sugra menjadi terkenal.

Panggilan untuk Sugra bermain tarling juga dilakukan pada acara puputan umah (peresmian rumah baru). Dalam peresmian rumah baru biasanya dilakukan dengan cara mengundang tetangga dan saudara untuk syukuran menempati rumah baru. Syukuran atau selamatan ini dilakukan agar yang menempati rumah baru nantinya memperoleh kebahagiaan dan keselamatan. Acara tersebut biasanya mengundang para tetangga sekaligus mengundang kesenian tarling.

Kesenian tarling juga biasanya turut meramaikan acara kebo lairan. Dahulu kampung-kampung di Indramayu, masyarakatnya memelihara kerbau. Tidak ada yang memelihara sapi. Kelahiran kerbau dianggap sebagai momentum mengumpulkan tetangga. Di situlah ada hiburan kesenian tarling dengan duduk lesehan, tanpa panggung, pulangnya Sugra diberi bekal makanan. Dari momenmomen seperti inilah nama Sugra mulai dikenal di kalangan masyarakat.
Memasuki tahun 1936, tarling yang Sugra tampilkan mulai mendapatkan honor. Pada tahun 1936 tersebut dapat dikatakan Sugra pertama kali mendapatkan honor berupa uang. Honor tersebut ia terima ketika Sugra mendapat undangan untuk menampilkan tarling di rumah Babah Pranti. Babah Pranti adalah seorang keturunan Cina dan sekaligus pemilik Toko Pranti. Toko Pranti yang berlokasi di Jalan Ahmad Yani Kabupaten Indramayu (sekarang toko Pranti sudah tidak ada). Babah Pranti merupakan orang yang menyukai tarling klasik. Setelah selesai bermain tarling, Sugra diberi imbalan uang seringgit.

Tahun 1936 itu musik tarling mulai mewabah. Masyarakat pun mulai membuat alat musik tarling seadanya. Di balik peralatan yang sederhana, tawaran untuk manggung terus berdatangan. Hingga suatu saat datang seorang sinden bernama Tuleg (1938) yang ikut bergabung. Kehadiran Tuleg membuat tarling Sugra semakin terkenal. Pada tahun 1938 Sugra dipanggil manggung hingga ke luar wilayah Indramayu, yaitu hingga ke Kabupaten Cirebon. Sugra diundang untuk bermain tarling oleh juragan Jana. Sugra kaget ketika pemuda di Kabupaten Cirebon tidak memperbolehkannya menggunakan kendang. Alasannya karena kendang dianggap kampungan jika digabungkan dengan gitar. Menurut mereka kendang hendaknya digantikan dengan celo (coatrabass). Akan tetapi rombongan Sugra tetap memainkan kendang.

Keikutsertaan Tuleg untuk bermain tarling bersama Sugra ternyata hanya mampu bertahan selama dua tahun, yaitu dari tahun 1938 sampai dengan tahun 1940. Tuleg akhirnya ikut bergabung dengan Muhsan di Jatibarang Indramayu. Dengan kondisi kesenian tarling pimpinan Sugra yang sedang beranjak maju, tiba-tiba ditinggalkan Tuleg sebagai sinden andalan dalam grup tarlingnya. Sugra pun akhirnya berpikir keras bagaimana caranya tarling yang ditampilkannya bisa tetap 
eksis. Sugra akhirnya memadukan tarling dengan pagelaran drama.

Tarling Sugra yang kemasannya diberi tambahan drama mengisahkan tentang protes sosial masyarakat Indramayu yang lekat dengan kehidupan warga pesisir yang marginal (Sasongko \& Suparta, 2014: 3). Tahun 1940-an, Sugra mulai melakukan pembaharuan dengan mengambil lakon Saedah - Saenih ${ }^{3}$ yang ${ }^{3}$ Saedah-Saenih cerita yang mengangkat kehidupan
rumah tangga. Ki Sarkawi yang bermatapencaharian
sebagai pencari kayu bakar di hutan, ia harus
menghidupi dua orang anaknya bernama Saedah (anak laki-laki nya) dan Saenih (anak perempuan). Pada saat Ki Sarkawi ditinggal istrinya karena meninggal, Sarkawi menikah lagi. Atas inisiatif istrinya dengan alasan ekonomi, Ny Sarkawi menghendaki agar kedua anaknya dibuang di hutan. Hanya berbekal sebungkus nasi, sesampai di hutan, Saenih merasa haus, dan pada saat minta air minum, menjadi kesempatan Sarkawi untuk meninggalkan kedua anak tersebut di tengah hutan dengan alasan mencari air minum. Ketika Saenih kehausan dan minta tolong kepada siapa pun yang mendengarnya, seorang kakek menanyakannya keadaan anak tersebut mengapa ada di hutan. Kakek tersebut menolong dan membawanya ke rumahnya. Suatu ketika, di kampung di mana kakek tersebut tinggal, terdapat pertunjukan tarling. Diajaklah Saenih ikut serta menonton tarling. Karena grup tarling tersebut tidak ada sindennya, oleh kakek tersebut Saenih diisuruh menggantikannya, akan tetapi Saenih tidak memiliki pengalaman dan suara yang belum memenuhi. Penonton tarling pun kecewa. Keadaan seperti ini diberitahukan kepada kakeknya, oleh kakeknya Saenih diberikan persyaratan seandainya akan menjadi sinden, Saenih agar menyanyi sebelum jam 12 malam. Syarat yang diberikan oleh kakeknya dipenuhinya, sehingga Saenih memiliki suara yang merdu. Saenih pun menjadi pesinden terkenal, nama Saenih mulai kesohor. Ketenaran Saenih terdengar oleh kakaknya Saedah. Saedah kemudian mencari dan menemukan tempat tinggal adiknya. Pada saat Saenih sudah dapat mengumpulkan uang, ia bermimpi, bahwa di depannya ada kereta api dengan cerobong asapnya menuju ke arah dirinya. Mimpi itu disampaikan ke kakaknya. Saidah menjawab bahwa mimpi Saenih tersebut melambangkan ajal akan menjemputnya. Dengan rasa sedih yang menggelayutinya, Saenih menitipkan sejumlah uang agar diberikan kepada orang tuanya. Saenih meninggal dunia. Walaupun telah meninggal, nama pesinden Saenih masih kesohor. Ketenarannya sampai terdengar oleh ayahnya. Ayah dan ibu tirinya mencarinya, akan tetapi ketika dapat menemukan di mana Saenih tinggal, orang tuanya hanya didramakan, kemudian lakon pegat balen. Cerita pegat balen mengangkat dari kehidupan seseorang yang menikah kemudian cerai, dan menikah lagi. Sugra juga menyuguhkan kiser monolog seperti kiser kedongdong, sunyaragi, dan jonggrang laut. Meskipun tanpa Tuleg, Sugra masih eksis memenuhi panggilan untuk memainkan sandiwara tersebut. Sugra dapat memainkan kesenian tarlingnya sekaligus memainkan drama Saedah-Saenih. Pada saat itulah, pertunjukan tarling Sugra dimulai dengan tatalu, bendrong, barlen, kiser, langgam carbon pegat, dermayonan, dan drama.

Pertunjukan tarling digelar sehari semalam yang terbagi ke dalam tiga pertunjukan. Pertunjukan siang dimulai pukul 11.00 s.d 16.00 WIB, yaitu tarling klasik dan guyonan. Pertunjukan malam dimulai pukul 20.00 s.d 24.00 WIB yang menampilkan pergelaran musik tarling humor. Pukul 24.00 sampai dengan pukul 03.00 WIB menampilkan drama kesedihan. Sesi ini diiringi dengan musik tarling klasik, instrumen goong, kendang, dan tutuk. Ciri khas dari pertunjukan drama tarling Sugra adalah adanya drama SaedahSaenih. Selain itu mengisahkan drama kasih tak sampai, kawin cerai, yang biasanya kisah-kisah drama tersebut diangkat dari latar belakang sosial dan budaya masyarakat agraris pesisiran Indramayu yang unik dan berbeda, misalnya hubungan orang miskin dan orang kaya, hubungan percintaan antara orang miskin dan orang kaya.

Pada 1 Maret 1942, tentara Pendudukan Jepang mendarat di Eretan

menemukan Saedah. Saedah menceritakan kalau adiknya telah meninggal dan menyerahkan titipan uang adiknya kepada orang tunya. Orang tuanya menerima titipan itu dan pulang kembali ke rumahnya. Di tengah perjalanan, mereka melewati Kali Sewo, di kali tersebut, mereka terjatuh hingga meninggal. Mayatnya dimakamkan di tepi kali tersebut (Dasuki, 1977: 337). Supali Kasim mengatakan makam di tepi Kali Sewo tersebut masih ada (Supali Kasim, wawancara, 15 Juli 2016). 
Wetan tepatnya di Kampung Susur Sereh Kabupaten Indramayu dan pada tanggal 3 Maret mereka telah masuk ke wilayah Indramayu. Tujuan selanjutnya untuk melanjutkan perjalanannya ke Kalijati Subang. Tanggal 8 Maret 1942, Pemerintah Belanda di Kalijati Subang yang diwakili oleh Carda Van Starkenborg dan Jendral Ter Porten menandatangani penyerahan tanpa syarat kepada Dai Nippon (Pemerintah Kekaisaran Jepang) (Widodo, Pikiran Rakyat, 21 Mei 1998). Sejak saat itulah Nusantara beralih kekuasaan dari Pemerintahan Belanda ke Tentara Pendudukan Jepang. Tempattempat yang pernah dibangun Belanda diambil alih dan dikuasai Jepang, seperti gedung pendopo Kabupaten Indramayu yang dijaga ketat oleh tentara Jepang. Tentara Pendudukan Jepang juga memberlakukan bagi rakyat pribumi yang melewati gedung pendopo tersebut baik yang jalan kaki maupun yang mengendarai sepeda agar berhenti untuk memberikan hormat. Bagi yang tidak memberikan hormat diberikan sanksi entah itu teguran atau pun pukulan (Dasuki, 1977: 263).

Saat kedatangan Jepang tersebut, suasana di Indramayu tampak mencekam. Sebagai tanda bahaya dibunyikanlah sirene atau kentongan, dengan demikian rakyat Indramayu berdiam diri di dalam rumah. Pada malam harinya lampu-lampu harus dimatikan dan tidak ada kegiatan di luar rumah. Selain menguasai gedung pemerintahan, tentara Jepang melarang segala bentuk organisasi baik sosial maupun kesenian. Sugra dan kawankawannya yang sering berkumpul untuk bermain tarling pun dilarang (Ramdhan, wawancara 17 Desember 2019).

Jepang hanya mengizinkan segala bentuk organisasi yang ditujukan bagi kepentingan Jepang. Pada saat itulah Jepang mendirikan organisasi militer dan semi militer yang wajib diikuti oleh semua rakyat. Untuk itu Jepang merekrut pemuda. Pemuda diperlukan Jepang untuk memperkuat garis belakang mereka. Mobilisasi pemuda diperlukan Jepang, bukan saja untuk kepentingan perang, tetapi juga untuk mempersiapkan pemuda agar mampu melawan Sekutu. Selanjutnya Jepang mendirikan barisan pemuda (seinendan) dan barisan pembantu polisi (keibodan). Kedua organisasi ini bertugas mempersiapkan pemuda, baik mental maupun moral untuk memberikan sumbangan pertahanan di garis belakang terutama di tingkat provinsi, desa, pabrik, dan perkebunan (Penerbitan Sejarah Lisan No. 4, 1988: 57-58). Dengan masuknya Jepang pada 1942, untuk sementara Sugra berhenti dalam bermain tarling.

Tahun 1945, Indonesia merdeka. Sugra kembali berkiprah di kesenian tarling. Tahun 1958, Sugra dan kawankawannya diundang ke rumah Babah Pranti untuk diperkenalkan dengan Gunawan. Kedatangan Gunawan ke Babah Pranti membawa sebuah kotak hitam yang tidak lain adalah alat perekam suara. Gunawan yang berasal dari Bandung tersebut merekam suara emas Sugra. Pada saat itu Gunawan menyiapkan sebuah kotak yang disimpan di atas meja. Sugra dan kawan-kawannya mulailah memainkan tarling. Tanpa Sugra sadari, sebenarnya suara Sugra sedang direkam dengan piringan hitam. Keesokan harinya, Babah Pranti yang rumahnya berdekatan dengan pasar Indramayu, memutar hasil rekaman suara Sugra dengan drama Saedah-Saenih. Suara Sugra yang keluar dari rekaman piringan hitam tersebut membuat orang yang lalu lalang ke pasar sengaja mendengarkan lantunan tarling Sugra, bahkan ketika sesi drama yang mengetengahkan cerita Saedah-Saenih, tidak sedikit orang yang mendengarkan, ikut hanyut dalam kesedihan dan meneteskan air mata. Bersamaan dengan itu, Sugra yang hendak ke pasar, tidak mengetahui kalau lantunan suara tarlingnya direkam oleh Babah Pranti. Ketika Sugra melewati rumah Babah Pranti, Sugra pun mendengar lantunan suaranya yang sedang diputar. Ia begitu heran, mengapa suaranya bisa menempel di kotak hitam tersebut. Sugra tampak 
malu tatkala orang yang sedang mendengarkannya pun menunjuk dirinya: "Oh ini dia orangnya yang menyanyi". Oleh karena merasa malu ketika tarling Sugra selalu diputar oleh Babah Pranti, ia pun menghindar untuk melewati rumah Babah Pranti. Untuk bisa menuju pasar akhirnya Sugra mengambil jalan lain (Supali Kasim, wawancara 17 Desember 2019).

\section{c. Fase Pengembang: Sugra sebagai Perintis dan Pendidik}

Penemuan sesuatu yang berbeda dari yang sudah dikenal sebelumnya itulah dinamakan inovasi (Tim Penyusun Kamus Besar Bahasa Indonesia, 2011: 538). Penemuan terhadap hal-hal yang baru meliputi jalannya unsur kebudayaan baru yang tersebar ke lain-lain bagian masyarakat, dan cara-cara unsur kebudayaan baru tadi diterima, dipelajari, dan akhirnya dipakai dalam masyarakat yang bersangkutan (Sukanto \& Sulistyowati, 2015: 274). Perjalanan Sugra dalam bermain tarling, meskipun dengan peralatan yang masih sederhana mampu menyedot perhatian masyarakat sehingga masyarakat Kepandean dapat bergabung dalam kesenian tarling. Dengan demikian Sugra pun dapat menghibur masyarakat pada saat hajatan dalam suasana duduk lesehan.

Seorang anak yang berasal dari Karangampel bernama Jayana ikut mempelajari nada-nada gitar. Jayana juga mendatangi Sulam, teman bermain Sugra (Supali Kasim, wawancara 17 Desember 2019). Begitu pula ketika Babah Pranti menyukai suara emasnya Sugra, orangorang yang melewati kediaman Babah Pranti pun ikut mendengarkan suara Sugra. Orang yang tadinya tidak mengenal Sugra, akhirnya dapat mengenalnya. Ketenaran Sugra sangatlah kecil akan tetapi pengaruh keahlian dalam bermain tarling sangat besar.

Memasuki tahun 1960-an, anakanak di pelosok Kabupaten Indramayu mulai dapat menerima kesenian tarling. Di tahun 1960 tersebut sejumlah tempat mulai bermunculan grup kesenian tarling. Di Desa Sleman, Kecamatan Jatibarang misalnya, mulai ada kesenian tarling. Sementara itu, Sugra hanyalah berdiam diri hingga di seputaran Kabupaten Indramayu. Berbeda dengan murid dan kawannya bermain tarling, Jayana dan Sulam, mereka berdua hijrah ke Cirebon dan memainkan tarling di sana. Jayana dapat menampilkan kesenian tarling yang memikat penonton. Tarling yang dibawakannya sangat sesuai dengan wilayah Pantura.

Di Cirebon, murid Jayana yang bernama Abdul Ajib mampu menciptakan kiser gancang, yaitu kiser sebagai ciri tarling yang lambat temponya dipercepat dan ada teks lagunya, sehingga muncul lagu Warung Pojok. Tarling kiser gancang ini mampu menyedot penggemar tarling. Selanjutnya muncul seniman-seniman tarling yang melengkapi alat musiknya dengan keroncong seperti Uci Sanusi. Ketika terjadinya fase pengembang ini, posisi Sugra tidak bisa menandinginya. Dapat dikatakan Sugra tidak menikmati sepenuhnya hasil kreasinya, yang menikmati justru generasi susudahnya, semisal penyanyi perempuan Dadang Dariah, Carini, pesinden sandiwara yang awal karirnya dari pemain tarling.

Industri hiburan seolah menyeleksi seniman mana yang disukai masyarakat, dan mana yang tidak. Sugra tidak mampu bersaing sehingga tidak dikenal di kalangan luas. Dalam fase pengembangan ini, Sugra kurang mampu bersaing, karena tarling yang dikemas Sugra bukan tarling sebagai industri, melainkan tarling klasik. Kenyataannya Sugra hanya mampu eksis di lingkup Indramayu. Walaupun demikian, Sugra telah melakukan edukasi yang menghasilkan seniman-seniman tarling menjadi besar, seperti Jayana (pemain tarling) dan Waraju (penyuling). Pada fase pengembang ini, di saat muridnya dapat mengembangkan tarling dengan inovasi-inovasi barunya, Sugra tidak dapat mengimbangi. 
Meskipun demikian Sugra dapat dikatakan sebagai perintis dan pendidik yang menjadikan seniman tarling menjadi besar karena Sugra menguasai ilmu musik dan tembang musik tarling. Ia juga memiliki olah vokal yang mumpuni. Jayana yang pernah belajar tarling kepada Sugra, sering diberikan saran dan nasihat mengenai olah vokal.

\section{d. Sugra sebagai Perintis Tarling}

Tahun 1997 Sugra meninggal dunia dan dimakamkan di Astana Bojong Kelurahan Bojongsari. Semasa hidup hingga akhir hayatnya, Sugra belum pernah mendapatkan penghargaan dari pemerintah setempat. Bentuk apresiasi terhadap Sugra mulai muncul pada tahun 2000 yang digagas oleh Dewan Kesenian Indramayu. Berdasarkan kajian dan pemikiran dari generasi muda dan para seniman Indramayu, khususnya para pemuda dari Desa Kepandean, mereka mencari identitas tarling dan menetapkan bahwa Sugra adalah perintis tarling.

Dalam sebuah pertemuan antara generasi muda dan seniman yang tergabung ke dalam Dewan Kesenian Indramayu, suara generasi muda diamini oleh Sunarto Nataatmadja dan muridmurid Sugra lainnya. Generasi muda yang ada di Kelurahan Kepandean merasa terketuk hatinya untuk melanjutkan kiprah Sugra dalam mengharumkan nama Indramayu sebagai tokoh perintis tarling. Mereka mengajukan sebuah penghargaan yang akan diberikan kepada Sugra. Dari pertemuan antara budayawan Indramayu dan generasi muda Kepandean, mereka mengajukan penghargaan yang kiranya pantas diberikan kepada Sugra (Tinus, A., wawancara 17 Desember 2019).

Pada 2012 Dewan Kesenian Indramayu memberikan penghargaan berupa plakat, piagam, dan uang yang diberikan kepada ahli waris Sugra. Selanjutnya mereka mengusulkan kepada pemerintah setempat untuk membangun gedung kesenian Indramayu. Pemerintah setempat menyetujui usulan tersebut, dan gedung kesenian tersebut diberi nama gedung kesenian "Mama Soegra". Kata mama diartikan sebagai bapak yang berpengaruh.

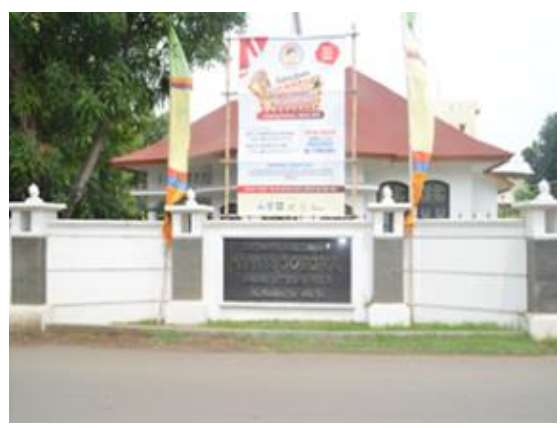

Gambar 2. Gedung Kesenian Mama Soegra Sumber: Dok. Penulis, 2019.

Di Kampung Kepandean, yang mana para pemudanya ingin berkreasi di bidang kesenian, rumah tersebut dimanfaatkan sebagai tempat berkumpulnya para pemuda. Mereka pun berinisiatif untuk mendirikan sebuah rumah yang diberi nama Griya Tarling. Tahun 2016 dibangunlah Griya Tarling sebagai wujud untuk mengenang jasa Sugra. Griya ini dijadikan sebagai tempat berlatih seni bagi pemuda-pemuda asal Kepandean. Tarling pun semakin diperkenalkan kepada masyarakat. Griya tarling ini pun akhirnya diberi nama Griya Sugra.

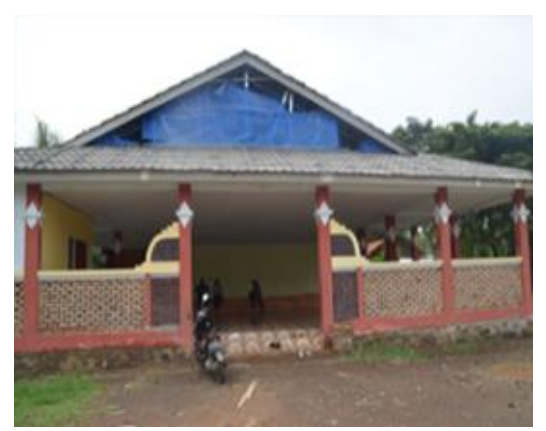

Gambar 3. Griya Soegra Sumber: Dok. Penulis, 2019.

Dewan Kesenian Indramayu juga mengapresasi usulan para seniman. Pada 2016 Andung Abdulgani membangun 
Tugu ${ }^{4}$ Tarling, yang menggambarkan dua orang bermain gitar dan suling. Tujuan dibangunnya Tugu Tarling tersebut sebagai penanda bahwa Sugra berasal dari Desa Kepandean.

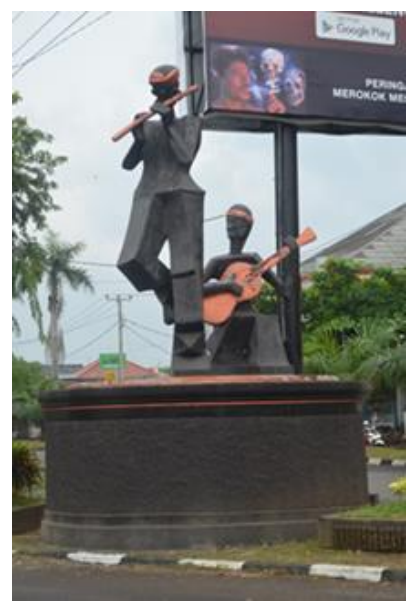

Gambar 4. Tugu Tarling

Sumber: Dok. Penulis, 2019.

Tanggal 17 Agustus merupakan tanggal yang sangat istimewa bagi bangsa Indonesia karena pada tanggal itu di tahun 1945, Republik Indonesia memproklamasikan kemerdekaannya. Bertepatan dengan momentum itu, setiap bulan Agustus masyarakat di berbagai daerah menghias jalan, halaman perkantoran, halaman rumahnya dengan nuansa merah putih. Sebagai wujud dari bentuk peringatan hari ulang tahun (HUT) kemerdekaan. Hampir di setiap kota dan kabupaten dapat dilihat betapa semaraknya warga masyarakat dalam memperingati HUT kemerdekaan Republik Indonesia. Di setiap jalan kecil atau pun gang-gang begitu semarak dengan hiasan lampulampu kecil, dan rangkaian bendera kertas merah-putih, ataupun menghias perkampungannya dengan aneka botol bekas yang diberi warna merah putih. Pada saat berlangsungnya puncak peringatan HUT kemerdekaan, masyarakat menyelenggarakan pentas seni dan lomba di lapangan yang luas dan terbuka.

Peringatan HUT kemerdekaan juga dilakukan oleh para pemuda di Kepandean Indramayu. Selain menghias kampung dengan bendera-bendera kertas merah putih, memasang umbul-umbul kain merah putih, mereka juga mengadakan pentas seni bertajuk "Gelaran Apresiasi Mengenang Maestro Tarling Sugra". Pentas seni yang dilaksanakan pada Peringatan HUT RI ke-73 (2018). Tujuan acara tersebut untuk mengenang Seniman Tarling Sugra, juga untuk membangkitkan kecintaan dan kebanggaan masyarakat Kepandean terhadap seni tarling, serta membangkitkan jiwa seniman tarling daerah Indramayu agar terus berkarya melestarikan kesenian asli Indramayu ini.

Acara tersebut dilaksanakan dalam upaya membangkitkan jiwa nasionalisme rakyat Kepandean dan untuk mengenang para pahlawan yang telah gugur dalam meraih kemerdekaan, serta untuk mengenang perintis tarling Sugra. Acara yang dilaksanakan pada hari Jum'at, 17 Agustus 2018 tersebut bertempat di Griya Tarling Sugra, Jalan Tanjung Pura, halaman sepak bola PORKI, Kepandean, Indramayu. Ketua panitia peringatan HUT RI ke-73, Ramdhan Ady Kristanto mengatakan bahwa kegiatan ini diselenggarakan untuk kembali membangkitkan kecintaan dan kebanggaan masyarakat Kepandean terhadap seni tarling dan mengembangkan jiwa-jiwa seniman tarling agar terus berkarya dan melestarikan kesenian asli Indramyu ini.

Acara tersebut didukung oleh Dinas Kebudayaan dan Pariwisata Kabupaten Indramayu. Pada acara tersebut juga tampil Nono, cucu sekaligus pemain tarling bersama Sugra.

4 Tugu adalah bangunan yang didirikan sebagai tanda umtuk mengingat peristiwa penting, peristiwa bersejarah, atau untuk mengormati orang atau kelompok yang berjasa (Tim Penyususan KBBI, 2011:1493). 


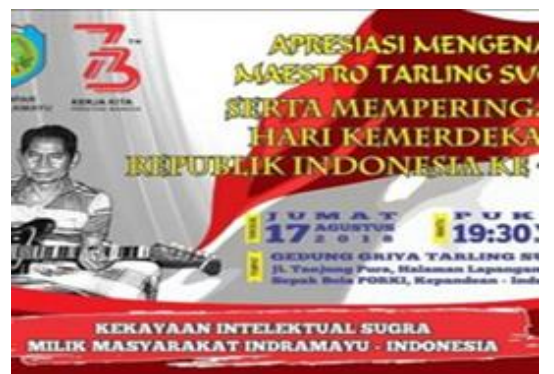

Gambar 5. Poster Kegiatan Mengenang Sugra Sumber: Dok. Penulis, 2019.

\section{PENUTUP}

Sugra merupakan orang pertama yang menggeluti tarling klasik di Indramayu. Ia masih menggunakan peralatan yang masih sederhana. Gitar yang dipetik pertama kali hanyalah gitar milik komisaris Belanda yang dinilai rusak dan diperbaiki oleh ayahnya, Talan. Ia pun hanya melantunkan lagu-lagu kiser. Tatkala Sugra harus memainkan gitarnya, Sugra pun membelinya dengan cara menabung hasil dari menjual padi. Pemuda Indramayu khususnya di Desa Kepandean mengikuti Sugra bermain tarling meskipun dengan peralatan yang masih sederhana dan menggunakan gitar buatan sendiri.

Sugra mengalami bermain tarling ketika belum ada lampu, panggung, dan peralatan yang modern. Ia hanya memainkan tarling dengan lesehan, ia pun belum mendapatkan honor, hanya mendapatkan suguhan makanan. Pertama kali Sugra mendapatkan honor itu dia dapatkan dari Babah Pranti. Babah Pranti merupakan salah satu warga yang menyukai tarling klasik.

Babah Pranti yang kemudian memperkenalkan Sugra pada Gunawan, orang yang merekam suara permainan tarling Sugra. Dari situlah Sugra mulai memasukkan drama tarling Saedah-Saenih. Sugra mulai dikenal di kalangan rakyat Indramayu. Grup tarling pun mulai bermunculan. Akan tetapi, di tengah gemerlapnya musik tarling khususnya yang berkembang pesat di Cirebon, pada saat itu Sugra tidak mengembangkannya, sebab ia hanyalah berkecimpung di lingkup Indramayu.

Kesenian tarling ini masuk ke dalam Warisan Budaya Tak Benda. Untuk usaha pelestarian, pemuda Kepandean sebaiknya dapat meneruskan jejak Sugra untuk terus bermain tarling baik di Griya Sugra atau di tempat lainnya.

\section{UCAPAN TERIMA KASIH}

Ucapan terima kasih saya haturkan kepada keluarga Sugra, Budayawan Supali Kasim, Ramdhan Adhy (pemuda Kepandean), Dinas Kebudayaan dan Pariwisata Kabupaten Indramayu.

\section{DAFTAR SUMBER}

Dasuki. (1977). Sejarah Indramayu. Indramayu: Pemda Kab. Indramayu.

Dede, P. (2015). Tonel: Teaterikalitas Pascakolonial Masyarakat Tansi Sawahlunto. Kajian Seni, 1 (02), 114129.

Hidayat, R. (2015). Seni Tarling dan Perkembangannya di Cirebon. Calls, 1 (1), 52-66.

Kasim, S. (2007). Tarling Migrasi Bunyi dari Gamelan ke Gitar Suling. Indramayu. Indramayu: Dinas Kebudayaan dan Pariwisata Kab. Indramayu.

Kasim, S. (2016). Sejarah, Syarah, Sejare-jare: Upaya Pemetaan Sejarah Indramayu, dalam buku Cimanuk Perspektif Arkeologi, Sejarah, dan Budaya. Cirebon: LovRinz Publishing bekerjasama dengan Panpel Festival Cimanuk 2016, Disporabudpar Kab, Indramayu.

Kasim, S. (15 Juni 2016 dan 17 Desember 2019). Wawancara.

Kuntowojoyo. (2003). Metodologi Sejarah, edisi kedua. Yogyakarta: Tiara Wacana.

Martaatmadja, S. (2016). Tarling Berasal Dari Indramayu. diakses 11 Mei 2020 dari http://www.KK291,1

FM.Indramayukab,go.id.

Muhsin, M. A. (2002). Filsafat Sejarah dalam Islam. Yogyakarta: Khasanah Pustaka Indonesia. 
Merlina, N. (2012). Tarling, Kesenian Tradisional Daerah Pantura. Patanjala, 4 (3), $497-510$.

Mulyani, Y. (2012), Teks Tarling: Representasi Sastra Liminalitas Analisis Fungsi dan Nilai. Metasasta, (5) 1, 92-101.

Nono. (17 Desember 2019). Wawancara.

Nugroho, A. (2016) Muara Cimanuk, Muara Kebudayaan: Simptom Geografis Sekaligus Estetis. Dalam buku Cimanuk Perspeltif Arkeologi, Sejarah, dan Budaya. Cirebon, LovRinz Publishing bekerjasama dengan Festival Cimanuk 2016 Disporabudpar Kab. Indramayu.

Penerbitan Sejarah Lisan No. 4. (1988). Di Bawah Pendudukan Jepang, Kenangan Empat Puluh Dua Orang yang Mengalaminya. Jakarta: Arsip Nasional Indonesia.

Ramdhan, A. (17 Desember 2019). Wawancara.

Salim. (2015). Perkembangan dan Eksistensi Musik Tarling Cirebon. Catharsis: Journal of Arts Education, (4) 1, 65-70.

Sasongko, G.W. \& Suparta, I.M. (2014). Lakon Tarling Sandiwara Istri Durhaka: Analisis Konflik Antar Tokoh dan Kritik Sosial. Diakses dari http://www.lib.ui.ac.id. FIB UI, hlm. 3.

Soekanto, S. (1985). Sosiologi Suatu Pengantar. Jakarta: Rajawali.

Soekanto, S. \& Sulistyowati, B. (2015). Sosiologi Suatu Pengantar. Edisi revisi Jakarta: Raya Gravindo Persada.

Sunardjo, U. (19843)., Meninjau Sepintas Panggung Sejarah Pemerintahan, Kerajaan Cerbon 1479-1809. Bandung: Tarsito.

Susanto, A. (1983). Pengantar Sosiologi dan Perubahan Sosial. Jakarta: Binacipta.

Tamburaka, R. E. (1999). Pengantar Ilmu Sejarah Teori Filsafat Sejarah Sejarah Filsafat dan Iptek. Jakarta: Rineka Cipta.

Tim Litbang Kompas. (2003). Profil Daerah Kabupaten dan Kota, Jilid 2, Kabupaten Indramayu. Jakarta: kompas.
Tim Penyusun KBBI, (2011). Kamus Besar Bahasa Indonesia Pusat Bahasa, edisi IV. Departemen Pendidikan Nasional. Jakarta: Gramedia Pustaka Utama.

Tinus, A. (17 Desember 2019). Wawancara.

Upandi, P. \& Hadi, Y. S. (2011). Gamelan Salendro, Gending dan Kawih Kepesindenan Lagu-lagu Jalan. Bandung: Ludruk Agung.

Widodo, J. (1998). Kesaksian Menjelang Jatuhnya Pemerintah Hindia Belanda Tahun 1942. Pikiran Rakyat $21 \mathrm{Mei}$ 1998. 